\title{
UMA LIÇÃO DE SUSTENTABILIDADE DOS RIBEIRINHOS DO PARANÁ DO LIMÃO, PARINTINS (AM)
}

\author{
Alberto Luiz Silva Ferreira ${ }^{1}$
}

Resumo: Este trabalho teve o objetivo de analisar o modo de agricultura familiar desenvolvido pelos agricultores estabelecidos em ecossistema de várzea na comunidade de Nossa Senhora de Nazaré, no paraná do Limão de Baixo, município de Parintins-AM, a luz do paradigma da sustentabilidade ambiental. $O$ diagnóstico de campo baseou-se em levantamentos multitemáticos e temáticos, organizados sob a abordagem sistêmica e estratégia interdisciplinar de atuação em estudos de casos, voltados para a realidade complexa e emergente das atividades de extrativismo, agricultura e pecuária da região. Constatou-se que a produção de hortaliças é realizada em canteiros suspensos, que permite às famílias geração de renda e segurança alimentar.

Palavras-chave: Ecossistema de Várzea; Agricultura Familiar; Sustentabilidade Ambiental.

Abstract: This work aimed to analyze the family farming method developed by farmers established in a lowland ecosystem in the community of Nossa Senhora de Nazaré, in the Paraná do Limão de Baixo, Parintins (AM, Brazil), in the light of the environmental sustainability paradigm. The field diagnosis was based on multithematic and thematic surveys, organized under the systemic approach and interdisciplinary strategy of acting in case studies, focused on the complex and emerging reality of the extractive, agricultural and livestock activities in the region. It was found that the production of vegetables is carried out in suspended beds, which allows families to generate income and food security.

Keywords: Várzea Ecosystem; Family Farming; Environmental Sustainability.

\footnotetext{
${ }^{1}$ Universidade Federal do Amazonas. E-mail: ferreiraalberto2009@gmail.com.
} 


\section{Introdução}

Este trabalho é o resultado de estudos realizados sobre a agricultura familiar desenvolvida por agricultores ribeirinhos estabelecidos nas várzeas do paraná do Limão de Baixo, afluente do rio Amazonas, na comunidade de Nossa Senhora de Nazaré no município de Parintins-AM, e teve como objetivo analisar o modelo de agricultura familiar praticado e sua interação com a economia de mercado, a partir de uma visão centrada no paradigma da sustentabilidade ambiental.

O tema agricultura familiar é muito caro para os habitantes da região amazônica. Por ser uma prática produtiva assentada na exploração de pequenas áreas de solo, com o uso praticamente exclusivo de mão de obra familiar, e que apresenta como finalidade precípua a segurança alimentar e como corolário a reprodução social das unidades de produção. Portanto, estas características da agricultura familiar coadunam-se com as características do bioma amazônico, que apesar de toda sua exuberância, tamanho e riqueza em biodiversidade, apresenta um equilíbrio bastante sensível, pois a retirada da floresta funciona como um gatilho que ameaça a fauna, a flora, os rios, lagos e igarapés e por que não até mesmo a sobrevivência humana.

Portanto, a relevância deste trabalho está em procurar perceber a maneira como o homem amazônico se relaciona como o meio ambiente através de uma atividade produtiva, o seu contato com a economia de mercado e as possibilidades de dinamização da atividade com a participação direta das famílias rurais bem como de ações que envolvam políticas públicas.

Objetivos: Geral: Analisar o modelo de agricultura familiar desenvolvido pelos agricultores familiares em ecossistema de várzea na comunidade de Nossa Senhora de Nazaré, no paraná do Limão de Baixo, rio Amazonas, município de Parintins. Específicos: Caracterizar os aspectos socioambientais da comunidade; levantar os recursos naturais, vegetais e animais, disponíveis para o uso e geração de renda na comunidade; identificar as técnicas de cultivos sustentáveis usados para a produção de alimentos; analisar a forma como acontece o relacionamento entre os agricultores produtores de hortaliças e a economia de mercado.

\section{Metodologia}

Este trabalho foi realizado a partir de uma pesquisa envolvendo aspectos qualitativos e quantitativos, com finalidade exploratória e descritiva (VERGARA, 2004, p.47-49); da comunidade Nossa Senhora de Nazaré, localizada em área de várzea, no paraná do Limão de Baixo, rio Amazonas, município de Parintins (AM). Os meios utilizados para a realização da pesquisa constaram de pesquisa bibliográfica, documental e de campo. A execução do diagnóstico de campo ocorreu por meio de levantamentos multitemáticos e temáticos, organizados sob abordagem sistêmica e estratégia interdisciplinar de atuação em estudos de casos, pela utilização do método proposto por YIN 
(2001) e suas técnicas na perspectiva de pesquisa qualitativa diante da realidade complexa e emergente das atividades de extrativismo, agricultura e pecuária da região.

Os levantamentos temáticos (agricultura, extrativismo, pecuária, socioeconômico e socioambiental) e a descrição dos processos produtivos e seus respectivos pontos de estrangulamento ocorreram mediante duas táticas para aprofundamento dos conhecimentos. A primeira, denominada de pesquisa de horizontalização multemática $(\mathrm{HM})$ e a segunda, verticalização temática (VT). Ambas trabalham com a visão dos atores sociais em situação de vivência e relato de experiência política e social do "aqui" e "agora", nas atividades produtivas nas várzeas (NODA, 2007).

Este instrumento não está livre de categorizar ou formalizar o material por ter conteúdo mais dinâmico, subjetivo, dialético na mão, por que ser mais flexível e perceber a trama não linear do fenômeno. Neste caso, o interesse pela representatividade estatisticamente garantida perde o seu lugar, porque se quer perceber a intensidade e não a extensão do fenômeno (NODA, 2007).

A estrutura do questionário formulário levou em consideração, algumas condições no processo da transformação dos depoimentos em informações e argumentos. O respeito por atitudes de prestar atenção, reconhecimento de conhecimento, de consideração à experiência foram o tom permanente nos momentos de contato para diagnósticos. Vale ressaltar, o fato dessa modalidade técnica de pesquisa de campo com o instrumental do questionário formulário não permitir generalizar extensivamente, mas intensivamente, por trabalhar com análise do discurso (NODA et al. p.13, 2007).

A unidade de amostragem para a horizontalização foi executada a partir da caracterização dos habitantes da comunidade e das propriedades individuais na área geográfica local. Para isso foram levantadas informações de instituições e organizações sobre localização e logística necessária para orientação amostral.

O questionário formulário elaborado para pesquisa teve como conteúdo anotações e registros dos ambientes acessado pelos habitantes da comunidade, atividades realizadas nas áreas de acesso ou de posse, dentre outras. O levantamento a partir deste instrumento permitiu observar: dados individuais sobre cada família, componentes do sistema de produção, unidade de paisagem, tamanho da área, tempo de ocupação, tempo de uso, tipo de sistema de cultivo, manejo ou extração, espécies cultivadas ou extraídas, preparo do solo, insumos utilizados, sanidade vegetal e animal, características do solo, dificuldades ou problemas nos sistemas de produção e finalidade de uso e destinação da produção.

\section{Aspectos gerais do município de Parintins (AM)}

O município de Parintins (AM) está localizado na 9a sub-região do Baixo Amazonas, latitude $-2^{0} 36^{\prime} 48^{\prime \prime}$ Sul e longitude $-56^{\circ} 44^{\prime}$ Oeste de Greenwich, a $50 \mathrm{~m}$ acima do nível do mara. A sede municipal, situada à margem direita do rio

revista brasileira educação ambiental 
Amazonas, na ilha de Tupinambarana, dista $369 \mathrm{~km}$ em linha reta da capital do Estado do Amazonas, Manaus; e $420 \mathrm{~km}$ por via fluvial. O município ocupa uma área territorial de $7.069 \mathrm{~km}^{2}$ (ITEPAM, 1983).

O município de Parintins (AM) limita-se com o Estado do Pará, iniciando na boca do igarapé da Valéria na margem direita do rio Amazonas, defronte da serra de Parintins; desta serra, pela linha geodésica que limita o Estado do Amazonas com o Estado do Pará, até alcançar sua inserção com o divisor de águas dos rios Andirá-Uaicurapá. Com o município de Barreirinha, começa na intersecção do divisor de águas dos Andirá-Uaicurapá com a linha geodésica que limita o Estado do Amazonas com o Estado do Pará, esse divisor, para norte, até alcançar a boca de cima no paraná do Ramos; este paraná, por sua linha mediana, até alcançar o furo das Coelheiras; este furo, por sua linha mediana, até alcançar o paraná do Limão; este paraná, por sua linha mediana, até alcançar o encontro do paraná do Limãozinho com o paraná do Urucurituba; este paraná, por sua linha mediana, até alcançar o lago Arapapá. Com o município de Urucurituba, começa na boca do lago do Arapapá, no paraná de Urucurituba. Desta boca, por uma linha, até alcançar a boca de cima do paraná do Mocambo., na margem esquerda do rio Amazonas; este rio, subindo por esta margem, até alcançar a localidade Ponta do Remanso. Com o município de Nhamundá, começa na margem esquerda do rio Amazonas, na Ponta do Remanso; subindo este rio até a Barreira do Paurá, desta Barreira, por uma linha, até alcançar as cabeceiras do igarapé do Aduacá, este igarapé por uma linha mediana, até alcançar a boca do paraná do Cabury; este paraná, por sua linha mediana até alcançar sua boca no lago do Cabury; o paralelo desta boca, para leste, até alcançar o paraná, por sua linha mediana até alcançar o rio Caldeirão, este rio, por sua lina mediana até alcançar sua confluência com a margem esquerda do rio Amazonas; desta confluência, por uma linha, até alcançar a confluência do igarapé da Valéria, na margem direita do rio Amazonas, defronte a serra de Parintins.

\section{Clima}

De acordo com a classificação de Koppen, o clima do município é "A" (tropical chuvoso), tipo Amw, que se caracteriza por apresentar uma estação seca de pequena duração. Entretanto, devido aos totais elevados de precipitação, possui umidade suficiente, para alimentar a floresta de características tropicais. A precipitação pluviométrica é sempre superior a $2.000 \mathrm{~mm} /$ ano. A temperatura média anual oscila em torno de $26^{\circ} \mathrm{C}$, com pequena amplitude térmica. A umidade relativa do ar é sempre superior a $80 \%$.

\section{Solos}

Ocorre predominância dos solos Latossolo Amarelo Álico e Argissolo Vermelho Amarelo Álico, na terra firme. Nas várzeas, o domínio é dos solos de aluvião, do tipo Gley Pouco Úmico Eutrófico, apresentando fertilidade natural média e elevada (IBGE, 2009). 


\section{Geomorfologia e Relevo}

O município de Parintins-AM localiza-se sobre formações quaternárias e terraços holocênicos. A unidade geomorfológica predominante é a planície amazônica, apresentando outras unidades morfoestruturais mais elevadas altimetricamente, que oferece maior segurança no período das enchentes dos rios. Ocorre também uma faixa de transição em planície fluvial. Trata-se de um domínio morfoclimático do tipo Azonal, ligado à permanência de lâmina d'água submetida ao regime fluvial do rio Amazonas. A leste do município encontra-se a "Serra da Valéria" com 137 metros de altitude.

\section{Hidrografia}

O município de Parintins-AM faz parte do maior sistema fluvial do mundo, a Bacia Amazônica. O rio Amazonas é o maior rio em volume de água do mundo, com um deflúvio médio anual estimado em $250.000 \mathrm{~m}^{3} / \mathrm{s}$. No trecho compreendido entre a foz do rio Nhamundá e a cidade de Parintins a sua largura é de aproximadamente $5 \mathrm{~km}$. O grande rio representa a via de escoamento e abastecimento, a grande estrada hídrica que liga Parintins à capital do Estado e ao Oceano Atlântico.

Os rios mais importantes dentro do município são: o paraná do Ramos; o paraná do Espírito Santo; o paraná do Limão; o rio Uaicurapá; o rio Mamurú. Ao longo dos rios destacam-se os lagos: o lago do Macuricanã; o lago do Aninga; o lago do Parananema; o lago do Macurany e a lagoa da Francesa, estes quatro últimos de vital importância quanto à sua preservação, uma vez que banham a sede municipal e estão mais suscetíveis à depredação e poluição.

\section{Aspectos gerais da comunidade de Nossa Senhora de Nazaré do paraná do Limão de Baixo}

Esta comunidade está localizada no paraná do Limão de Baixo, afluente da margem direita do rio Amazonas na região do Baixo Amazonas, em Parintins, a aproximadamente cinco quilômetros da cidade de Parintins, cujo meio de transporte é o fluvial. A comunidade limita-se a leste com a cidade de Parintins, a oeste com o lago do Moratinga na comunidade de São José do paraná do Limão do Meio, ao norte com o rio Amazonas e pelo sul com terras de várzea que alcançam até o paraná do Ramos no município de Parintins.

A comunidade por estar localizada em um ecossistema de várzea, sofre todos os anos com o fenômeno da subida e descida das águas do paraná do Limão de Baixo (Figura 1). Normalmente, a enchente começa no mês de novembro. Acontecendo o auge da cheia ou enchente nos meses de abril a junho. O período de descida das águas ocorre a partir do mês de junho, atingindo o pico da seca nos meses de setembro e outubro. 


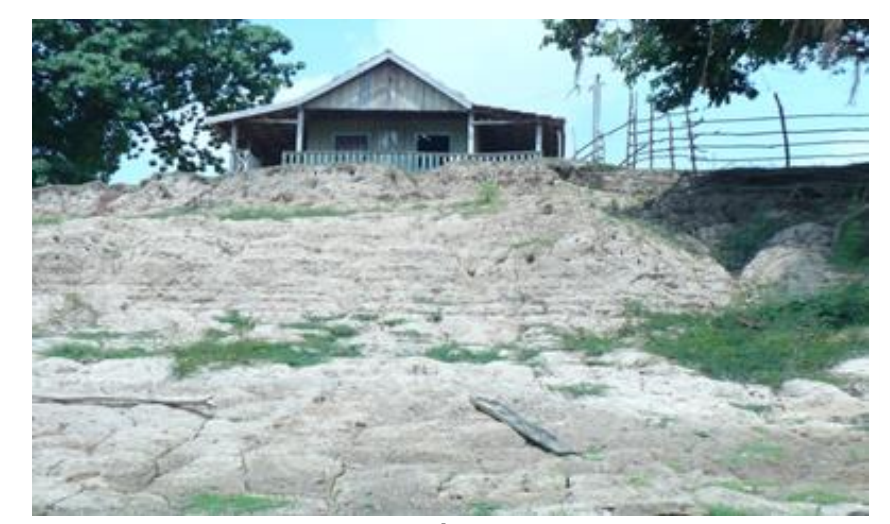

Figura 1: casa ribeirinha do paraná do Limão de baixo. Fonte: o autor.

Dependendo do nível de subida das águas o volume de deposição de sedimentos varia, implicando na fertilidade do solo. O clima da região é caracterizado por dois períodos bem definidos, o quente e chuvoso e, o quente e sem chuvas, todos dois, porém sempre com umidade elevada. O período chuvoso normalmente se inicia pelo mês de dezembro, estendendo-se até o mês de julho.

A população da comunidade de Nossa Senhora de Nazaré do paraná do Limão de Baixo é constituída quase que na sua totalidade de agricultores familiares de baixa renda, pescadores, agricultores e criadores de animais de pequeno porte (aves, carneiros e porcos) e gado bovino e bubalino, os últimos compondo rebanhos variando de 30 a 50 animais. Pecuaristas com rebanhos acima de 1000 animais também aproveitam as pastagens naturais na época da vazante.

\section{O ecossistema de várzea amazônico}

No que se refere às planícies, a variedade dos ecossistemas é muito grande, tal é o dédalo do mosaico terra/água, sobretudo no caso do médio e baixo Amazonas. Na larga planície de 14 a 35 quilômetros de largura, sucedem-se e se repetem faixas anastomosadas de ecossistemas no meio dos numerosos setores deprimidos ou ligeiramente "altos" da rasa planície. Pouca gente sabe que o rio Amazonas, nos setores considerados, é um dos cursos d'água que transporta a maior carga de sedimentos finos em solução, acrescidos de mini touceiras de vegetação flutuante, na face da Terra. Os contrastes entre as águas escuras do rio Negro e as águas amarelo pardacentas do Solimões/Amazonas indica atributos hidrobioquímicos e hidrogeomorfológicos (AB'SABER, 2002, p.158).

Para quem faz pesquisas nos confins de Mato Grosso, no extremo norte de Tocantins ou no centro do Maranhão é fácil saber onde começa a Amazônia. Quando as florestas deixam de ser apenas galerias amarradas ao fundo aluvial dos vales; quando as matas sobem e fecham as vertentes e interflúvios das colinas onduladas, onde antes, para o sul, o sudeste e o leste existiam extensos cerrados; ou ainda, quando cerrados e matas secas cedem 
lugar para intermináveis florestas de "terra firme": aí começa a Amazônia. Em várias faixas de contato entre cerrados e matas na periferia da Amazônia ocorrem mosaicos complexos de paisagens de retalhos de chapadões ou baixos platôs com cerrados, e colinas onduladas e serrinhas com matas de "terra firme" ou orográfica. Maior complexidade ainda ocorre quando existem campestres pontilhados de arboretos dos cerrados (Roraima), passando gradualmente para matas de "terra firme" (Mucapai, Caracas) ou campos cerrados transicionando

para matas orográficas (centro-oeste de Roraima, centro-sul do Amapá). A rigor, em todas as grandes manchas de campestres ou cerrados que se estendem ao norte do rio Amazonas - a saber, campos de Boa Vista, cerrados de Monte Alegre, cerrados naturalmente degradados do Amapá - ocorrem contatos complicados entre as formações abertas e o início das grandes matas que as envolvem (AB'SABER, 2002, p.158).

No caso particular da larga e longa planície amazônica, desde a barra do rio Negro até as proximidades do golfão Marajoara, o desdobramento dos ecossistemas da própria faixa de aluviação é extraordinário. O rio Amazonas permanece centralizado no meio da grande planície que construiu ou (re)elaborou no decorrer do Holoceno. O rio se destaca bem no meio das terras baixas, parcialmente submersíveis, embutidas entre tabuleiros. Aqui não é o rio que se estende de "barreira" a "barreira" da outra margem. Sem a sua planície aluvial, o rio tem de quatro a seis quilômetros de largura; a planície que ele elaborou por processos hidrogeomorfológicos possui de catorze a trinta e cinco quilômetros de extensão lateral. Trata-se de um mosaico terra água labiríntico, extremamente diversificado: diques marginais baixos outrora florestados, ultrapassados pelas águas durante as grandes cheias; florestas de várzeas altas em alguns setores em que a planície encosta-se na base dos tabuleiros; réstias de florestas biodiversas em diques marginais interiorizados; campinas em volutas de areia branca de riachos meândricos já desaparecidos; vegetação herbácea ou campestre em leitos abandonados; capins nativos nas bordas de lagos de várzea, expostos ou submersos, em função da retração ou reexpansão das águas. E, por fim, uma assimetria berrante de ecossistemas nas margens dos paranás, em um caso que florestas de "terra firme" recobrem tabuleiros, barrancas altas ou taludes de terraços da banda interna dos aludidos canais laterais descontínuos (os falsos rios dos franceses); o yazoo river dos norte-americanos), enquanto da outra banda estende-se uma multidão de ecossistemas terrestres, aquáticos e subaquáticos das planícies aluviais labirínticas. Na faixa desse verdadeiro mosaico terra/água, interposta entre o paraná e o rio Amazonas propriamente dito, ocorrem ecossistemas muito diferenciados entre si, ainda que pertencentes a uma só família do ponto de vista hidrogeomorfológico (AB'SABER, 2002, p.158). 


\section{Caracterização das unidades de produção da várzea do paraná do Limão de Baixo, comunidade de Nossa Senhora de Nazaré, no Rio Amazonas}

Dentro da realidade produtiva agrícola do Brasil dois modelos de estruturas organizacionais apresentam-se, ainda que com as características não definidas claramente: de um lado temos a agricultura patronal, empresarial ou agronegócio; do outro temos a agricultura familiar que abrigaria conceitualmente todos aqueles produtores que não estivessem incluídos no primeiro caso (FEIJÓ, 2011, p.129). O modelo de agricultura familiar apresentase pulverizado em milhões de unidades produtivas, porém capaz de apresentar-se altamente eficiente em relação a questão de segurança alimentar, alocação de mão de obra e distribuição de renda (ABRAMOVAY, 2007).

As unidades de produção familiar da comunidade de Nossa Senhora de Nazaré do paraná do Limão de Baixo - rio Amazonas, apesar de apresentarem diferentes atividades para o aproveitamento satisfatório dos recursos naturais disponíveis, constituem-se de unidades agrárias de área reduzida em virtude de serem terras que foram divididas em partilha de herança e de maneira informal, isto porque essas terras não podem ser tituladas, existindo uma forma de domínio tradicional, rigorosamente respeitada, inclusive com campos negociados, mas que não têm titulação reconhecida pela legislação brasileira .

Dentre as diferentes atividades desenvolvidas no cotidiano e ao longo do ano pelas famílias ribeirinhas estão: o cultivo de hortaliças folhosas em canteiros suspensos ou "balcões" como são conhecidos regionalmente; a criação de pequenos rebanhos de gado bovino misto; a criação de animais de médio e pequeno porte como porcos, galinhas, patos e perus; a fabricação artesanal de queijos de coalho e manteiga e, a atividade extrativista da pesca. Alguns comunitários dominam a técnica da carpintaria e quando necessário executam trabalhos de reparos em canoas e barcos construídos em madeira e mesmo a construção de casas de madeira.

Possivelmente pela forma de utilização dos recursos naturais a disposição, bem como pela proximidade da sede do município, a cidade de Parintins, a região do paraná do Limão de Baixo, uma área de várzea formada pela influência do rio Amazonas, não apresenta mais recursos naturais na floresta e nos ambientes aquáticos que sejam atrativos economicamente e despertem a cobiça de pessoas estranhas a região. A utilização em tempos passados das terras ribeirinhas ao paraná do Limão de Baixo para o plantio das culturas da juta (Corchorus capsularis) e da malva (Pavonia malacophyla) para a extração de suas fibras iniciou o processo de erradicação de muitas espécies da flora nativa; com a decadência dessas culturas na região e o começo da produção de hortaliças para comercialização o processo de derrubada da floresta se acentuou em virtude da necessidade de madeiras para a construção dos canteiros bem como das passarelas utilizadas pelos produtores para os tratos culturais das hortaliças. 
A proximidade da sede do município - cerca de trinta minutos de barco a motor em transporte pelo rio; na época de verão pleno os comunitários mais jovens deslocam-se para a cidade por terra utilizando motocicletas - ao mesmo tempo em que concorreu para a erradicação de espécies da fauna e flora em virtude da intensa exploração predatória, possibilitou o desenvolvimento da atividade produtiva do cultivo de hortaliças em canteiros suspensos haja vista a proximidade do mercado consumidor. No início a atividade produtiva de hortaliças apresentava uma variedade maior de espécies sendo cultivadas: couve (Brassica oleraceae sp.), alface (Lactuca sativa sp.), pimentão (Capsicum annum), tomate (Lycopersicum esculentum), coentro (Coriandrum sativum), cicória (Erygium foetidum), cebolinha (Allium fisculosum), pimentas diversa (Capsicum sp.), maxixe (Cucumis anguria), berinjela (Solanum melongena). Atualmente, a produção está restrita apenas as culturas da couve, cebolinha, coentro, chicória e pimentas diversas. Essa atividade desenvolveuse paralelamente a criação de pequenos rebanhos bovinos (Figura 2), que além do fornecimento do esterco para o substrato de plantio das hortaliças nos canteiros suspensos, também apresentam a função de poupança, haja vista a facilidade de liquidez quando necessário sua comercialização, nesse caso tanto da carne como dos derivados do leite.

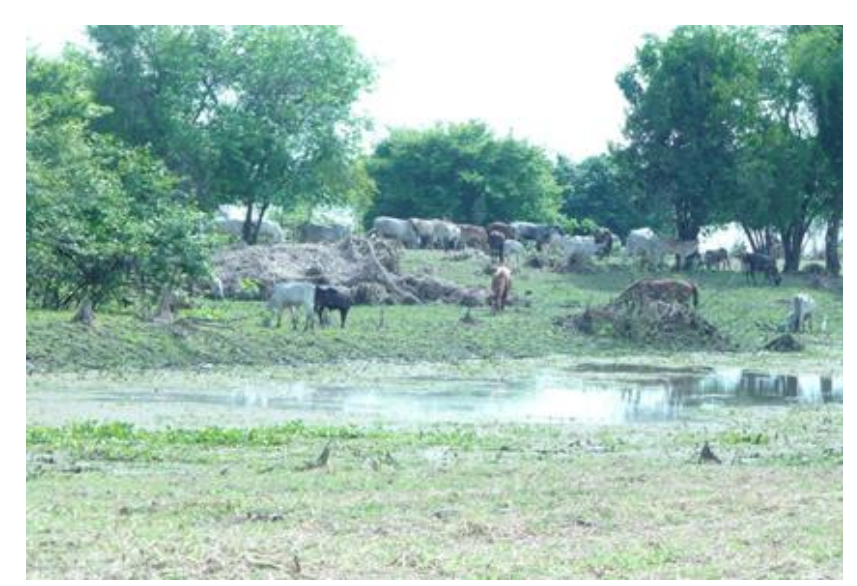

Figura 2: rebanho bovino em pasto de várzea. Fonte: o autor.

Com relação a força de trabalho empregada na atividade produtiva, praticamente na atualidade resume-se ao casal - marido e mulher - essas pessoas já apresentam idade avançada, algumas já aposentadas e outras já próximas da aposentadoria. Essa escassez de mão de obra apresenta causas e consequências sobre a atividade produtiva.

A principal causa da escassez de mão de obra apontada pelos comunitários diz respeito a necessidade de continuação dos estudos por parte dos jovens e adolescentes nativos. Essa mobilidade se deve ao fato de que a única escola municipal da comunidade funcionar como classe multisseriada alunos em diferentes anos de escolaridade juntos - e apresentar baixos resultados, além do que em virtude da subida das águas e da cheia do rio, durante o período da enchente as aulas são suspensas, reiniciando apenas 
com a chegada da vazante das águas. Como algumas famílias adquiriram residências na sede do município e outras possuem parentes e amigos lá residindo, os adolescentes/jovens normalmente são encaminhados para a cidade onde ficam aos cuidados dos irmãos mais velhos, parentes ou amigos.

Apesar de não se ter feito referência à ocupação da mão de obra juvenil por ocasião da pesquisa, ficou claro que além dos estudos os jovens buscam na cidade uma ocupação no mercado de trabalho que lhes proporcione uma renda, ainda que para isso passem a desempenhar trabalhos braçais haja vista sua pouca qualificação profissional, a ideia é de que o trabalho proporciona renda para a subsistência familiar.

Como consequência da escassez da mão de obra a capacidade de produção das unidades de produção familiar diminuiu significativamente, impactando na quantidade e variedade de produtos produzidos para o mercado, pois cada casal procura trabalhar de acordo com sua disponibilidade de tempo e força produtiva. É importante assinalar o nível de organização apresentado por unidade de produção, onde os produtores procuram ter todas suas atividades planejadas de forma a obter um nível ótimo de rendimento, estas unidades funcionam como pequenas organizações a exemplo das organizações manufatureiras ou de serviços, ou seja, cada unidade de produção é gerida a partir de princípios da administração como planejamento, administração de recursos humanos, organização, coordenação e controle.

Cada atividade produtiva apresenta características próprias, dessa forma a execução das mesmas deve acontecer de forma independente ainda que em alguns casos uma venha concorrer para a execução de outra, como por exemplo, o manejo do gado possibilita a produção do esterco para o cultivo das hortaliças, contudo são atividades que diferentemente da linha de produção de uma organização de serviços ou manufatureira não podem ser executadas a partir do modelo de uma linha de produção, isto devido sua base natural, pois o fato é que a agricultura conserva-se uma atividade fundamentalmente tributária da natureza e dependente de elementos biológicos sobre cujo ritmo e sequência o controle humano é limitado. Submetida a forças naturais e ao fato de lidar com elementos vivos, a agricultura enfrenta obstáculos insuperáveis no processo de divisão do trabalho, pelo menos no estágio atual da agricultura familiar da região do paraná do Limão de Baixo.

Ainda que neste trabalho o escopo seja a análise da produção de hortaliças em canteiros suspensos, de forma alguma as outras atividades desenvolvidas nas unidades de produção familiar devam ser consideradas como de menor importância, pois havemos de considerar a unidade de produção como um sistema em que cada atividade ou elemento contribui para a sobrevivência do mesmo, tendo para isso participação na formação da renda familiar.

Como o modelo de unidade de produção pesquisado destina toda a produção de hortaliças para o mercado da cidade de Parintins - apenas o básico é utilizado no consumo familiar - e a renda monetária gerada por tal 
produção é reduzida, as demais atividades como a criação de gado bovino, a criação de pequenos animais e a pesca funcionam como um suporte ou complemento da renda familiar, além dos benefícios sociais do governo federal como aposentadorias, bolsa família e seguro defeso para os pescadores.

\section{O sistema de produção de hortaliças em canteiros suspensos ou balcões}

Visualmente, o modelo de cultivo em balcões é de uma beleza ímpar. Cachos de tomates e frutos de berinjela como que flutuando sobre as águas do rio, os canteiros aparentemente submersos nas águas. Para Noda, (2007, p.31) "o sistema de produção tem como base, práticas agroflorestais de produção caracterizadas pelo manejo das terras numa integração, simultânea e sequencial, entre árvores e/ou animais e/ou cultivos agrícolas". Os canteiros suspensos ou "balcões" como são conhecidos regionalmente, são estruturas construídas em madeira resistente ao contato com a água. O tempo de duração depende do tipo de madeira utilizada, sendo que os esteios ou estacões apresentam tempo de vida bastante longo se comparado ao tempo de vida das tábuas e ripões que também são utilizados na construção dos canteiros. Em média as madeiras como tábuas e ripões duram em torno de cinco anos, já os estacões ou esteios chegam a durar mais de dez anos. São utilizados ainda na construção dos canteiros fios de arame recozido que prendem as peças que formam os canteiros.

As estruturas são construídas com estacas de 2,5 a $3,5 \mathrm{~m}$ que servem de sustentação para os canteiros forrados com tábuas estreitas de $20 \mathrm{~cm}$ (Figura 3). Cada canteiro possui de 15 a $20 \mathrm{~m}$ de comprimento, com $80 \mathrm{~cm}$ de largura e profundidade de $12 \mathrm{~cm}$. Atualmente toda a madeira para a construção das estruturas é adquirida da região dos rios Uaicurapá e Tracajá, locais para onde os produtores transferem seus rebanhos bovinos por ocasião das enchentes.

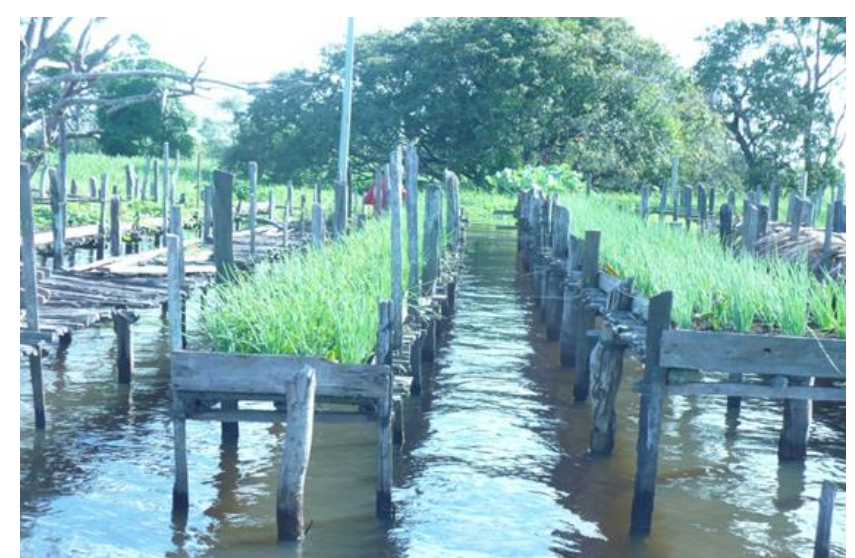

Figura 3: canteiros em período de enchente. Fonte: o autor.

A partir da enchente do ano de 2009 (uma das maiores registrada no rio Amazonas) os produtores, como forma de prevenção têm utilizado estacões 
mais compridos, para elevar a altura dos balcões e evitar prejuízos com a perda das hortaliças cultivadas.

Por ocasião do período da vazante dos rios, é o momento em que o gado retorna da terra firme para a engorda nos campos naturais de várzea. Daí, os agricultores recolhem todo o esterco produzido para usar na composição do substrato onde serão cultivadas as hortaliças; esse esterco é armazenado em locais cobertos ou mesmo a céu aberto.

Cada unidade de produção possui entre quinze a vinte canteiros, os canteiros novos são preenchidos com o esterco armazenado durante o verão e os demais já em cultivo, irão recebendo esterco gradativamente, dependendo da necessidade de reposição. Esse manejo é uma forma tradicional de cultivo.

\section{Manejo das culturas nos canteiros de plantio}

A prática do cultivo de hortaliças em canteiros suspensos é realizada a partir de conhecimentos transmitidos através das gerações, de pai para filho, ou mãe para filha (Figura 4). As inovações tecnológicas decorrem da procura por parte dos próprios produtores para possibilitar maior produtividade em sua atividade, mesmo na ausência de assistência técnica por parte dos órgãos oficiais na região do paraná do Limão de Baixo. Cada cultura tem um sistema tradicional de produção desde a semeadura até a colheita.

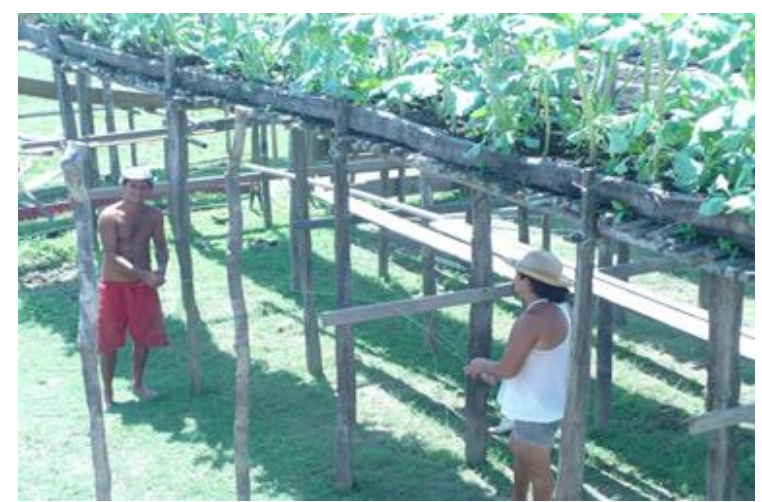

Figura 4: casal de agricultores sob canteiros em período de seca. Fonte: fonte o autor

A cultura do coentro (Coriandrum sativum) é multiplicada a partir de sementes que são adquiridas no comércio da cidade de Parintins. As sementes são depositadas em sulcos diretamente nos canteiros, em seguida cobertas com folhas de palmeiras até a germinação quando então são retiradas. Quando maduras as plantas são então arrancadas e o substrato de cultivo é revolvido e uma nova quantidade de esterco é então adicionada ao canteiro que será imediatamente plantado com nova cultura, podendo ser até mesmo o coentro (Figura 5). 


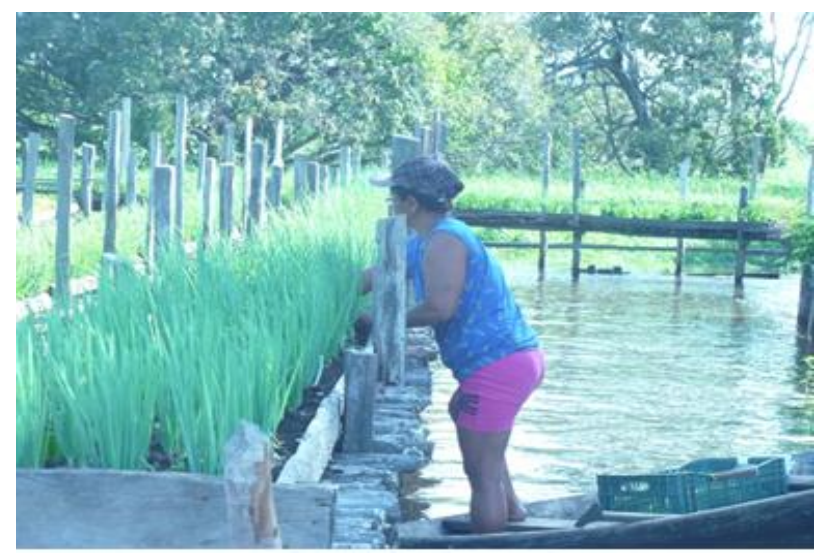

Figura 5: agricultora trabalhando dentro de canoa. Fonte: 0 autor.

A cebolinha (Allium fistulosum) é multiplicada a partir de propágulos existentes na propriedade, normalmente os produtores quebram folha por folha para a comercialização e, somente quando os pseudobulbos já estão velhos é que são arrancados para a comercialização. Uma parte, contudo, é separada para os novos plantios. Dessa forma a renovação do esterco se dá com as plantas nos canteiros e, somente quando ocorre a retirada por completo das plantas é que se procede a renovação total do substrato.

Com as espécies, couve (Brássica olerácea sp.) e chicória (Erygium foetidum) o procedimento é parecido ao da cultura da cebolinha. Como as folhas dessas culturas são colhidas individualmente para a comercialização, o substrato de plantio vai sendo renovado gradativamente e, apenas quando os produtores decidem pela renovação das matrizes é que o substrato é renovado completamente. As culturas da couve, chicória e pimenta também são multiplicadas a partir de materiais genéticos existentes nas propriedades, sendo desconhecidos por parte dos produtores a denominação correta das cultivares ou mesmo a sua origem. A couve, também é multiplicada a partir de brotações que nascem nas axilas das folhas e, a chicória é a partir de sementes coletadas das plantas cultivadas.

\section{A rotina de uma unidade de produção}

Quando não é dia de mercado o casal divide-se entre as tarefas de cuidar dos canteiros, cuidar das galinhas, patos e porcos - o que inclui alimentação, agasalhar ou "sentar" as galinhas e patas para desovar e chocar, separar os pintos; cuidar do gado - tratar de ferimentos, pastorear as vacas prenhes, cuidar dos bezerros "enjeitados", tirar o leite para a venda "in natura" e fabricação de queijos de "coalho" e "manteiga", consertar cercas e currais; pescar. Participando praticamente de todas as atividades já citadas as mulheres ainda têm a incumbência das atividades domésticas.

A preparação dos produtos para o mercado é feita no dia anterior da comercialização nas feiras da cidade de Parintins. Essa atividade começa ao amanhecer, estendendo-se até o momento em que o sol começa a esquentar, 
por volta das oito horas da manhã, para não prejudicar o material colhido. Este é depositado na varanda da residência e coberto com pano umedecido. É feita, então, uma parada para o almoço e o descanso dos agricultores.

No início da tarde é feita a preparação das hortaliças para a comercialização. Os maços de cheiro verde constam de cebolinha, coentro e chicória. Dependendo do tamanho das folhas, a couve é amarrada em maços de quatro ou mais folhas. Na manhã seguinte, antes do raiar do sol as hortaliças são acondicionadas em caixas de isopor com capacidade para 180 litros e transportadas para a sede do município de Parintins.

A escassez de mão de obra reflete no tamanho das áreas cultivadas com hortaliças por família. Essas áreas variam de duzentos metros quadrados a seiscentos metros quadrados, enquanto as espécies cultivadas se restringem a cebolinha, coentro, chicória, couve manteiga e pimentas do tipo ardida e doce. Essa portanto, seria a capacidade de produção de uma unidade de produção.

Em função da variedade de produtos hortícolas comercializados nas feiras, atacadistas de hortifrutigranjeiros e supermercados da cidade de Parintins, verifica-se que existe um mercado que apresenta oportunidades de negócios bastante vantajosas para os produtores locais.

O quadro de produtos hortícolas comercializados na cidade de Parintins e produzidos regionalmente e importados de outras regiões apresenta-se da seguinte forma: os produtos de produção local são a alface, cebolinha, coentro, chicória, couve manteiga, pimentas ardidas e doce ou de cheiro. Produtos produzidos em outras regiões do próprio município ou importados de outros Estados: agrião, alface-crespa, batata-doce branca, batata-doce vermelha, batata-inglesa ou portuguesa, berinjela, cebolinha, cebola branca de cabeça, cebola roxa de cabeça, chicória, coentro, couve brócolis, couve-flor, couve manteiga, jambu, jerimum/abóbora, macaxeira, pepino, pimentas ardidas, pimentas-de-cheiro ou doce, pimentão amarelo, pimentão vermelho, pimentão verde, quiabo, repolho branco, repolho roxo, tomate, cenoura.

\section{O encontro com o mercado}

O transporte até a cidade é realizado em canoas de madeira grandes movidas a motor de 5,0 HP. Estas embarcações são conhecidas regionalmente como bajaras e não dispõem de coberturas, tanto que é comum as senhoras fazerem o uso de guarda-sóis quando da viagem de retorno para a comunidade por volta do meio dia.

Cada família produtora realiza duas viagens por semana e comercializa em torno de 500 unidades de produtos por viagem. Por ocasião das entrevistas os produtores foram um tanto evasivos quanto ao valor do preço de venda das hortaliças, segundo os agricultores os valores variam de trinta e cinco a cinquenta centavos por maço/unidade, recebendo o pagamento em dinheiro. Por se tratar de produtos frescos e, os produtores já estarem há tempos 
envolvidos na atividade praticamente toda produção já possui compradores certos e antecipados.

O porto mais utilizado pelos produtores da comunidade de Nossa Senhora de Nazaré do paraná do Limão de Baixo é a conhecida Baixa de São José (Figura 6). Neste local são realizadas as vendas diretamente aos consumidores e revendedores de hortaliças de Parintins. Outro porto utilizado para venda de hortaliças é o da rampa do mercado central da cidade de Parintins. Após a venda dos produtos, os produtores normalmente aproveitam para comprar mercadorias necessárias para o consumo da família.

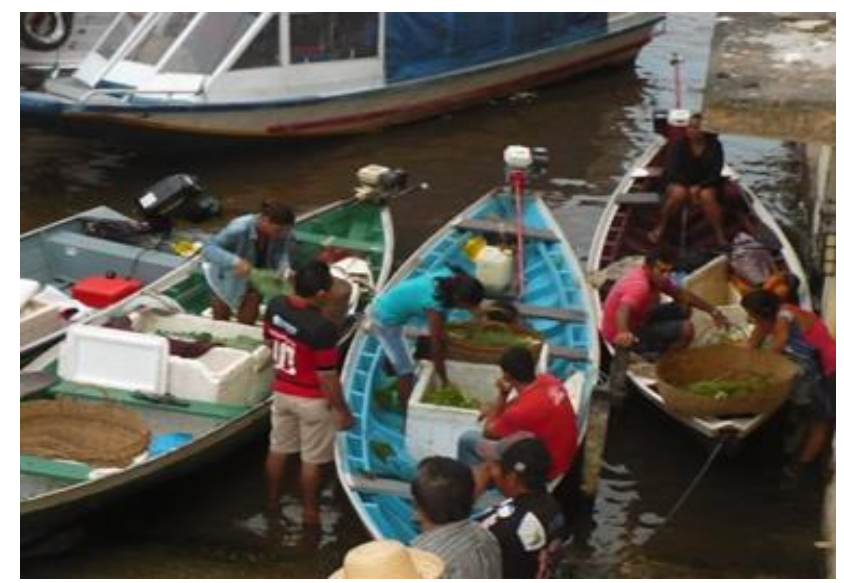

Figura 6: comercialização no porto da cidade. Fonte: o autor.

O relacionamento do ribeirinho amazônico com os agentes sociais da economia de mercado, impondo padrões na qualidade, regularidade e qualidade na oferta de produtos (NODA, 2007), alterou o relacionamento das populações tradicionais no seu cotidiano com a natureza. De extrator a produtor foi um processo que levou o homem amazônico a executar trabalhos ligados à "agricultura e ao extrativismo animal e vegetal em que o planejamento, produção, comercialização e consumo são diretamente organizados pelas famílias (NODA apud SCHERER, 2006).

\section{Aspectos populacionais e de mão de obra da comunidade}

A população da comunidade de Nossa Senhora de Nazaré do Limão é constituída por famílias tradicionais da localidade e outra parte é constituída por famílias de vaqueiros que prestam serviços aos pecuaristas estabelecidos na região e que residem na cidade de Parintins. Isto quer dizer que em determinadas épocas do ano - período da cheia dos rios - apenas as famílias tradicionais permanecem na comunidade. Nesta comunidade foram detectadas 25 famílias, totalizando um número de 47 pessoas formadas por crianças, jovens, adultos e idosos vivendo efetivamente. Destas, treze famílias trabalham com a produção de hortaliças.

A mão de obra ativa é praticamente constituída somente pelos casais, sendo bastante reduzida. O número de jovens que poderia dar sua contribuição 
como força de trabalho nas atividades de produção é insignificante. Do total de famílias que trabalham com a produção de hortaliças a força de trabalho representa $59 \%$ da população, incluindo três pessoas já aposentadas e que ainda continuam na ativa. O outro grupo mais representativo da população é o de crianças de até 10 anos. Contudo ainda estão na comunidade porque a escola local ainda oferece formação compatível com sua faixa etária. Segundo os pais dessas crianças, assim que eles necessitarem dos níveis de escolaridade mais avançados, serão encaminhados para a cidade de Parintins, onde terão oportunidade de dar prosseguimento aos estudos. É importante observar que a composição da idade dos casais que formam a mão de obra ativa apresenta todos os homens acima dos trinta anos, cinco deles estão acima dos cinquenta anos e um está próximo dos setenta anos. Com relação as mulheres sete delas estão acima dos quarenta anos, quatro já ultrapassaram os cinquenta anos e uma está entrando nos setenta. Isso representa um quadro de trabalhadores com sua maioria próxima da aposentadoria.

\section{Aspectos relacionados à composição da renda familiar}

A composição da renda das famílias da comunidade de Nossa Senhora de Nazaré é característica de muitas outras famílias que também trabalham com a agricultura familiar. Essa renda é formada a partir de diversas fontes como a pecuária, o extrativismo animal através da pesca, os benefícios sociais do governo federal, além de salários pagos pela municipalidade, essa realidade não é diferente do que ocorre em outros municípios do Amazonas.

A partir da declaração dos próprios comunitários, temos uma formação de renda anual e calculada em salários-mínimos das treze famílias entrevistadas em que se apurou uma renda total de 277,13 salários-mínimos, dividiu-se esse total pelos cinco itens que compõem a cesta da renda das famílias da localidade. Pela análise do quadro verificou-se que os itens que mais pesam na formação da renda são as hortaliças e os benefícios sociais, com $62 \%$ e $20 \%$ respectivamente, vindo em seguida a pecuária com $8 \%$ e, fechando o quadro os recebimentos de salários do município e a renda obtida da pesca com $5 \%$ e $4 \%$ respectivamente.

A perspectiva com relação a formação da renda familiar dos comunitários da localidade é que os benefícios sociais venham a ocupar um lugar de destaque em poucos anos, seguidos da pecuária. É evidente a preocupação dos comunitários em manter as fêmeas bovinas no plantel para a reprodução e consequentemente aumento dos rebanhos. Isto se deve ao fato dos produtores considerarem a atividade pecuária menos demandante de mão de obra, além do que no período das enchentes os animais podem ser transferidos para as terras firmes evitando com isso os prejuízos decorrestes do regime das águas dos rios. Em vista dessa perspectiva é natural que a renda oriunda da produção de hortaliças venha a diminuir no decorrer dos anos vindouros. 
Fatores que interferem na organização social e espacial da produção no sistema de produção de várzea na região do paraná do Limão de Baixo rio Amazonas

Regularização fundiária - praticamente todas as unidades de produção da comunidade de Nossa Senhora de Nazaré do paraná do Limão de Baixo estão situadas dentro de propriedades em que foram realizados processos informais de partilha de herança, ou seja, os pais ou avós dividiram suas propriedades e autorizaram os filhos e netos a construírem suas casas e instalarem suas unidades de produção, sem que houvesse a necessária titulação fundiária legal.

Mão de obra - praticamente em todas as unidades de produção a mão de obra disponível é a do casal, alguns iniciando a formação de famílias e, outros já em idade próxima da aposentadoria, outros já se aposentando. As poucas crianças existentes na comunidade esperam apenas completar o estudo fundamental para serem encaminhadas a casa de parentes na sede do município.

Assistência técnica - os agricultores foram unânimes em afirmar que a única assistência oficial que recebem é do IDAM (Instituto de Desenvolvimento Agropecuário e Sustentabilidade Ambiental do Estado do Amazonas) órgão oficial do Estado para prestação de serviços de extensão rural. Uma das principais atividades da Instituição é a prevenção da febre aftosa, nas campanhas estaduais de vacinação. Com relação à assistência técnica na produção de hortaliças não existe nenhuma ação por parte dos órgãos governamentais, sendo citada inclusive a EMBRAPA (Empresa Brasileira de Pesquisa Agropecuária) que já possui uma unidade instalada na cidade de Parintins, porém até agora não realizou nenhuma ação na região do paraná do Limão de Baixo.

Crédito rural governamental - em virtude da falta de regularização fundiária das propriedades da região e da ausência de assistência técnica por parte dos órgãos oficiais de extensão rural e pesquisa, os produtores não têm acesso ao crédito oficial o que dificulta o investimento em inovações e tecnologias que venham dinamizar o processo produtivo, assim como a possibilidade de ampliação das estruturas de produção.

Enchentes - a partir do ano de 2009 em que ocorreu uma das maiores enchentes da bacia hidrográfica do rio Amazonas, causando grandes prejuízos aos agricultores de várzea, os produtores do paraná do Limão de Baixo que tiveram a perda de cem por cento de seus canteiros cultivados com hortaliças, foram obrigados a investir em novas estruturas de plantio o que implicou em gastos extras com a aquisição de madeiras e o trabalho para a construção das novas estruturas. Além disso, algumas famílias tiveram que investir em madeiras novas, principalmente esteios mais compridos para elevar o assoalho das casas, para continuar morando mesmo que com o desconforto de subir escadas mais altas. 
Secas - o período do verão amazônico, quando as chuvas rareiam, as temperaturas diurnas se elevam e os ventos aumentam de intensidade e duração, o ressecamento dos substratos dos canteiros - que possuem pouca profundidade - prejudica o desenvolvimento das plantas. É um período em que o consumo de gasolina se eleva pela necessidade que os agricultores têm de irrigar as plantas pela manhã e a tarde, usando água captada muito longe, da parte mais baixa do rio.

Preço dos insumos, materiais e equipamentos - os insumos mais utilizados pelos produtores de hortaliças e que têm sua aquisição fora da localidade são a gasolina e algumas sementes. A gasolina é o combustível utilizado nos equipamentos de irrigação, assim como nas canoas motorizadas - bajaras - de transporte. A gasolina utilizada para a irrigação o ano todo, tem seu consumo bastante elevado no período da vazante/seca o que leva os agricultores a serem cautelosos na utilização dos referidos equipamentos, quanto mais seco o leito do paraná mais gasolina é consumida na atividade de irrigação. As sementes de coentro e alface como são comercializadas em uma única casa de comércio especializada em artigos para agropecuária na cidade de Parintins, apresentam o preço bastante elevado se comparado aos preços praticados nos comércios da cidade de Manaus, capital do Estado. A madeira utilizada na construção dos canteiros é um fator que contribui significativamente para a elevação dos custos de produção das hortaliças. Essa madeira atualmente é adquirida na região dos rios Uaicurapá e Tracajá, região do ecossistema de terra firme - onde as águas não inundam a floresta e sofre a concorrência dos preços praticados na cidade de Parintins, o preço por peça é considerado bastante elevado pelos produtores. As peças mais utilizadas pelos produtores são os estacões, as tábuas e os ripões utilizados na construção dos canteiros e nas passarelas existentes entre os canteiros e que também ligam os mesmos as residências. Essas passarelas são utilizadas pelos agricultores para realizarem a prática dos tratos culturais nas plantas cultivadas o que inclui o enchimento dos canteiros com o esterco, plantio de mudas ou semeio do coentro, revolvimento e complementação do substrato de plantio.

Organização de produtores - apesar do espírito de ajuda mútua que contribui para a existência da comunidade, quando a questão diz respeito a organização dos produtores em associação, cooperativa, sindicato ou qualquer outro organismo com objetivos associativistas há rejeição por parte dos agricultores. Por ocasião da pesquisa pôde-se perceber que os produtores já tomaram no passado a iniciativa de organizar-se em uma associação, mas hoje os mesmos são reticentes a tal iniciativa. Outros produtores filiados ao sindicato rural de Parintins não procuraram mais a instituição por acharem que ela não trazia nenhum benefício para os sindicalizados. Alguns produtores procuram filiar-se a Colônia $Z-17$ de Pescadores do município de Parintins assim como ao Sindicato de Pescadores de Parintins (SINDIPESCA) com o objetivo de receber o seguro-defeso, uma ajuda financeira do governo federal 
para os pescadores artesanais no período em que a pesca fica proibida em resguardo ao período de reprodução de algumas espécies de peixes na região.

\section{Conclusões}

O presente trabalho teve como objetivo analisar o modelo de agricultura familiar praticado pelos agricultores da comunidade de Nossa Senhora de Nazaré do paraná do Limão de Baixo, município de Parintins-AM e, sua interação com a economia de mercado, a partir de uma visão centrada no paradigma da sustentabilidade ambiental.

A agricultura familiar como atividade econômico-produtiva contempla unidades de produção quase sempre instaladas em áreas reduzidas, utilizando precipuamente a mão de obra familiar e, com sua característica de diversidade de atividades contribui significativamente para a segurança alimentar das unidades de produção familiares, além do mais esta atividade econômicoprodutiva influencia significativamente na geração de renda e trabalho nas pequenas cidades do interior do Brasil. Todas estas características foram observadas nas unidades de produção no trabalho de pesquisa desenvolvido na comunidade de Nossa Senhora de Nazaré do paraná do Limão de Baixo. Além do que o envolvimento maior das unidades de produção familiares com a economia de mercado local vem se acentuando com o passar dos anos em virtude das mudanças ocorridas nos hábitos e costumes dos comunitários em demandarem cada vez mais de produtos e serviços ofertados pelo mercado como elemento do macroambiente em que estão inseridos. $O$ fato da comunidade estar localizada em um ecossistema de várzea da comunidade amazônica obriga os produtores locais a adequarem suas atividades produtivas e seu modo de viver ao ambiente, o que contudo não deixa de apresentar significativas alterações ambientais, principalmente no que diz respeito a biodiversidade haja vista a satisfação das necessidades de sobrevivência da população residente.

Nesse processo de análise buscou-se respostas para indagações como: os agricultores locais estão atendendo as exigências do mercado no que diz respeito a quantidade, a qualidade e variedade de produtos? A oferta de mão de obra local seria suficiente para atender as necessidades da atividade produtiva? Se em caso negativo, quais os fatores que interfeririam nessa variável ambiental? A atividade recebeu inovações tecnológicas que estimulassem a produtividade e o interesse dos jovens em continuar na atividade? A introdução de novos produtos atraiu o interesse dos consumidores e comerciantes e criou dificuldades para a importação por parte dos atacadistas de hortifrutigranjeiros da cidade de Parintins-AM? A produção a partir de métodos naturais é fator de atração para os consumidores?

Com a análise dos dados coletados em campo chegamos a conclusão que é evidente que a atividade de produção de hortaliças em canteiros suspensos na região do paraná do Limão de Baixo vem sendo paulatinamente 
substituída pela pecuária mista, assim como outras fontes de renda estão suprindo as necessidades da população existente atualmente na localidade. Ainda que a atividade possa explorar um mercado francamente favorável com a expansão contínua da demanda e o valor de comercialização dos produtos hortícolas, a ausência de políticas públicas de apoio a atividade cria uma situação de abandono dos agricultores familiares, que descapitalizados, sem assistência técnica, capacitação tecnológica, organização e estruturas de apoio como sistemas de irrigação, transporte e portos adequados procuram outras atividades ou mesmo outras fontes de renda para o sustento de suas famílias.

Para a cidade de Parintins-AM torna-se muito interessante 0 investimento público nas ações que envolvam a agricultura familiar, quando se observa que a atividade gera fora das unidades de produção na zona rural, ou seja, na cidade, uma cadeia de serviços que impactam a economia local dinamizando a renda e o mercado de trabalho urbano. Essa cadeia envolve estivadores do porto, transporte urbano e rural, armazenamento, comerciantes atacadistas e varejistas, indústria caseira de alimentos naturais e outros.

A diminuição da mão de obra levou os produtores locais a reduzir a área plantada bem como a variedade de espécies cultivadas em um claro movimento de racionalidade que evitasse sacrifícios laborais além do necessário. Por intuição ou por uma estratégia deliberadamente planejada a formação de pequenos rebanhos bovinos, inicialmente destinados à formação de poupança, preparou algumas famílias para o momento atual em virtude das mudanças em curso.

Como a formação de renda das famílias é um composto de diversas fontes: venda de produtos hortícolas, venda de carne, leite e seus derivados, venda de pequenos animais, benefícios sociais do governo federal e salários de familiares residentes na cidade é natural que o impacto da diminuição da renda semanal gerada a partir da produção e comercialização de hortaliças tenha sido minimizado.

A ausência de políticas públicas que contemplem diretamente a população de produtores familiares do ecossistema de várzea do paraná do Limão de Baixo é um fator de significativa importância para o atual estado de esvaziamento populacional da localidade bem como para o abandono gradual da atividade de produção de hortaliças em "balcões", mesmo que, como demonstrou a pesquisa do ponto de vista econômico a mesma se apresente viável, este um dos pilares do desenvolvimento sustentável. Investimentos públicos em capacitação, tecnologias e divulgação de informações, aliados aos serviços fundamentais como educação, saúde, energia e fornecimento de água com qualidade seriam fundamentais para a permanência de uma população adaptada as condições de vida amazônica evitando com isso transferências para localidades que quase sempre são hostis para populações oriundas do ambiente rural. O conceito de sustentabilidade seria limitado se fizesse referência apenas a questão ambiental (SACHS, 2008, p.71-72), para o autor outras dimensões constituem o amplo arcabouço formado pelo conceito que 
para o mesmo envolveria: a sustentabilidade social como a própria finalidade do desenvolvimento; a sustentabilidade social como corolário; a sustentabilidade do meio ambiente como consequência da social; a sustentabilidade econômica aparece como uma necessidade sem contudo, constituir-se como condição prévia para as outras e, a sustentabilidade política que permite a governabilidade. Os investimentos citados anteriormente influenciariam sobremaneira na qualidade de vida de cidadãos deixados a margem das decisões governamentais, além do que complementariam o tripé em que se assenta o conceito de desenvolvimento sustentável de ser socialmente justo, economicamente viável e ecologicamente correto. Lembrando que o desenvolvimento alicerçado no paradigma da sustentabilidade ambiental deve acontecer de forma integral e como um processo histórico de apropriação universal pelos povos da totalidade dos direitos humanos individuais e coletivos; as políticas públicas que permitem a governabilidade do processo de reconciliação do desenvolvimento com a conservação da biodiversidade devem garantir os direitos das futuras gerações o que conduz a um duplo imperativo ético "a solidariedade sincrônica com a geração atual e a solidariedade diacrônica com as futuras gerações (SACHS, 2008).

\section{Referências bibliográficas}

ABRAMOVAY, R. Paradigmas do capitalismo agrário em questão. - 3, ed. - São Paulo: Edusp, 2007.

AB'SABER, A. N. Bases para o estudo dos ecossistemas da Amazônia brasileira. Estudos Avançados; v.16, n.45, p,152 - 165, 2002.

AMAZONAS. Álbum cartográfico dos municípios do Estado do Amazonas, Gov. do Amazonas, ITEPAM, Manaus, 1983

BRASIL. Lei $\mathbf{n}$. 11.326/2006. Estabelece as diretrizes para a formulação da Política Nacional da Agricultura Familiar e Empreendimentos Familiares Rurais. 2007.

SCHERER, E.; OLIVEIRA, J.A. (orgs.). Amazônia: políticas públicas e diversidade cultural. Rio de Janeiro: Garamond, 2006.

FEIJÓ, R.L.C. Economia agrícola e desenvolvimento rural. Rio de Janeiro: LTC, 2011.

ITELPAM. Álbum cartográfico dos municípios do Estado do Amazonas. Gov. do Amazonas, Manaus, 1983

NODA, S.N. (org.). Agricultura familiar na Amazônia das águas. Manaus: Editora da Universidade Federal do Amazonas: Edua, 2009.

SACHS, I. Caminhos para o desenvolvimento sustentável. - 3. ed. - Rio de Janeiro: Garamond, 2008.

SACHS, I. Desenvolvimento: includente, sustentável, sustentado. Rio de Janeiro, Garamond, 2008.

YIN, R. Estudo de caso: planejamento e métodos. Tradução Daniel Grassi. 2. ed. - Bookman, 2001. 